\title{
THE EFFECT OF DIFFERENT PREPARATION TIMES ON THE TAPER AND SHAPE OF SIMULATED ROOT CANALS USING THE XP-ENDO SHAPER ROTARY FILE
}

\author{
Mohamad A. Kedra ${ }^{1}$, Ahmed M. Farghaly ${ }^{2}$ Ashraf S. Refai ${ }^{3}$
}

\begin{abstract}
Objective: This study evaluated the effect of different preparation times on the taper and shape of simulated root canals using the XP-endo Shaper rotary file. Materials and methods: A total of 54 resin blocks made of clear polyacrylic resin with simulated root canals were used in this study. They were photographed using a built-in camera of a stereomicroscope. They were prepared using the XP-endo Shaper instrument up to the working length (WL) according to the manufacturer's recommendation for 30 seconds (s), $60 \mathrm{~s}$ and 90s. Postoperative photographs were performed after canal preparation at each time-point. Then, the registered pre and postoperative datasets were examined to evaluate the canal taper and apical tip diameter. Repeated measures general linear model was used to compare the differences in either the increase or the reduction of the parameters amongst the time-points. Alpha-error was set at 5\%. Results: Extending the period of XP-endo Shaper active instrumentation at WL significantly influenced several parameters such as apical tip diameter $(\mathrm{P}<0.05)$ and canal taper $(\mathrm{P}<0.05)$ of the instrumented canal. Conclusions: Extending the activation time of XP endo Shaper instruments at WL resulted in a more comprehensive root canal preparation, increasing the canal taper and the apical tip diameter.
\end{abstract}

KEYWORDS: Stereomicroscope, Simulated canals, shaping ability, XP-endo Shaper.

\section{INTRODUCTION}

The primary goal of root canal treatment is to create a bacteria free environment through adequate cleaning and shaping using different instruments, irrigants materials and techniques ${ }^{(1,2)}$. Conventionally, cleaning is accomplished using various irrigants materials like sodium hypochlorite, ethylenediaminetetraacetic acid (EDTA), hydrogen peroxide and chlorohexidine gluconate ${ }^{(3)}$. Later on, strategies for root canal cleaning and disinfection have been directed to use irrigation activation techniques, such as: sonic, ultrasonic and many other methods ${ }^{(4)}$. In order to achieve proper cleaning, effective shaping is mandatory ${ }^{(5)}$. Shaping procedures should respect the canal anatomy through maintaining the original canal curvature and preventing the creation of procedural errors such as: zipping, ledging and canal transportation ${ }^{(6)}$.

However, the root canal system is anatomically complex and offers many challenges such as: narrow canals, canal curvatures, canal calcifications, as well as irregular canal cross sections ${ }^{(7,8)}$. Many instruments and instrumentation techniques have been introduced to overcome these challenges, such

1. Demonstrator, Department of Endodontics, Faculty of Dental Medicine (Cairo-Boys), Al-Azhar University.

2. Professor of Endodontics, Faculty of Dental Medicine (Cairo-Boys), Al-Azhar University

3. Associate Professor of Endodontics, Faculty of Dental Medicine (Cairo-Boys), Al-Azhar University

•Corresponding author: mohamedabdeen.209@azhar.edu.eg 
as rotary Nickel Titanium instruments (NiTi) which have become an integral part of instrumentation for the last 25 years ${ }^{(9,10)}$. Many rotary NiTi instruments have been introduced with wide differences in instrument design, metallurgy, method of manufacture and kinematics, all these characteristics aim to improve flexibility, cutting efficiency and resistance to fracture ${ }^{(11)}$. For instance, the ProTaper Next rotary file has an unusual rectangular cross section and is manufactured out of modified NiTi alloy called M-Wire ${ }^{(12)}$.

On the other hand, the Hyflex rotary file is made out of a new NiTi alloy called CM-Wire and is manufactured using a new technique called Electric Discharge Machine which aims to reduce the risk of instrument fracture ${ }^{(13)}$. Furthermore, the ProTaper Gold rotary file combines a new metallurgy of M-Wire and reciprocating kinematics rather than continuous rotation ${ }^{(14-15,16)}$. All the previously mentioned instruments are solid cored instruments which depend on their core to create the canal shape.

More recently a new instrument, the XP-endo Shaper (FKG Dentaire SA), has been introduced. It incorporates an unusual design which depends on the rotation of the instrument to produce the canal shape rather than the instrument core. The XP-endo Shaper is manufactured out of MaxWire (Martensite-Austenite alloy) and has a parallel non tapered form with a triangular cross section. The instrument has a core size corresponding to number \#30 ISO instrument, and is manufactured in an S-shape curve. Outside the patient's mouth, the instrument's S-shape corresponds to a size number $1 \%$ taper (Martensitic phase), when placed in the patient's mouth with the temperature above $35^{\circ} \mathrm{C}$, the instrument changes to a size number $4 \%$ taper (Austenitic phase). The manufacturer suggests that this instrument is used for a total of one minute inside the canal space to enlarge the canal size to a size number \#30, 4\% taper $^{(17)}$. However, up till now there has been no research to evaluate the effect of increasing or decreasing the preparation time on the intended canal shape when using the XP-endo Shaper.

\section{SUBJECTS AND METHODS}

A total of 54 resin blocks made of clear polyacrylic resin with simulated root canals were used in this study. The simulated root canals were $16 \mathrm{~mm}$ in length and with 0.02 taper, radius of curvature $5.5 \mathrm{~mm}$ and at a 45-degree canal curvature (Endo Training Block-S, Dentsply Maillefer). Prior to experimentation, the resin blocks were photographed from the side showing the canal curvature using a stereomicroscope (Leica QWIN V3 image analyzer computer system ). For the purpose of image standardization, a custom-made platform made of clear polyacrylic resin was constructed $(9.5 \mathrm{~cm}$ length, $4.5 \mathrm{~cm}$ in width and $1 \mathrm{~cm}$ in height). At one end of the platform, a slot was made to house the resin blocks ( $1 \mathrm{~cm}$ height X $0.5 \mathrm{~cm}$ depth $X 3 \mathrm{~cm}$ length). An endodontic ruler was cemented onto the resin platform -just above the slot covering a small part of the slot for the purpose of referencing the real dimensions of the canals in relation to that of the image taken pre or post-instrumentation. The platform was fixed to the stereomicroscope in a specific position using double-faced tape ( $3 \mathrm{~m}$ double-faced tape).

Prior to imaging, all canals were filled with blue ink (Corfix, porto alergi, chinase) using an insulin syringe to define their outlines and facilitate evaluation. Then each block was inserted into the slot in the platform and a pre-instrumentation image was taken at $8 \times$ magnification then uploaded to a cloud-based electronic system.

\section{Canal preparation and grouping:}

Prior to a canal preparation, canal patency was established using a \#10 k-file (Dentsply Maillefer, Switzerland) followed by a \#15 k-file (Dentsply Maillefer, Switzerland). The canal space was irrigated with $3 \mathrm{ml}$ of preheated $\left(37^{\circ} \mathrm{C}\right)$ distilled water using a 30-gauge side-vented needle (ultradent, South Jordan, Ut ) attached to a disposable plastic syringe. Then a new XP-endo shaper file (FKG Dentaire, La Chaux-de-Fonds, Switzerland) was 
mounted on a torque-controlled motor (E-cube, saeshine, korea) and activated at rotational speed of $800 \mathrm{rpm}$ and torque of $1 \mathrm{Ncm}$ according to the manufacturer's instruction ${ }^{(18)}$. Prior to instrumentation, the manufacturer's rubber stopper was removed and replaced with a customized teflon stopper $(10 \mathrm{~mm}$ thickness and $5 \mathrm{~mm}$ diameter) to standardize the working length to be $15 \mathrm{~mm}$ and prevent the file from exceeding that length.

\section{Canal preparation was divided into two phases:}

\section{Phase one:}

Preparation of the canal until the file reached the full working length for the first time. The XP-endo shaper file was used with an in and out motion and the file was advanced to the full working length in 10 strokes at a rate of 2 strokes/ 3 second (15 seconds). After reaching the full working length the instrument was removed, and the canal was irrigated with $2 \mathrm{ml}$ of distilled water and recapitulated using a \#15 K-file.

\section{Phase two:}

Preparation after the file reached the full working length for the first time. Prior to initiation of phase two all blocks were divided into three groups randomly ( $\mathrm{n}=18$ per group) according to the total time of preparation:

Group 1: (XP-1) the canals in this group were shaped using the XP-endo shaper for $1 / 2$ a minute.

Group 2: (XP-2) the canals in this group were shaped using the XP-endo shaper for 1 minute.

Group 3: (XP-3) the canals in this group were shaped using the XP-endo shaper for 1.5 minutes.

The instrument was reinserted into the canal and the preparation was continued at the same rate for the specified amount of time for each group. In order to simulate clinical conditions, all preparation procedures were done while the resin blocks were placed inside a water bath at $37^{\circ} \mathrm{C}$.
Post-instrumentation imaging of the resin blocks was done as mentioned previously except that the contrast ink used in post-instrumentation images was red in color to differentiate between the pre and post-instrumentation canal shapes.

\section{Evaluation of the canal preparation:}

All pre- and post-instrumentation images were imported to a computer software (AutoCAD 2016, Autodesk, San Rafael, CA, USA) for evaluation. The evaluation was done by an endodontist who was blinded to the parameters of the study.

\section{1- Evaluation of canal taper:}

\section{A. Adjustment of images and drawing of interval lines:}

After importing the images into the computer software, a composite image was produced by superimposition of the pre- and post-instrumentation images of the same block. To ensure accurate superimposition, the reservoirs of the blocks were used as a reference. Prior to establishing the level of the first interval line, the booster tip of the XPS instrument was measured to be $(0.566) \mathrm{mm}$. When evaluating the blocks, the level of the first interval line was determined by subtracting 0.566 $\mathrm{mm}$ form the beginning of the divergence of the canal preparation of the original canal and this was considered the level of the first interval line. Then 10 interval lines were drawn using the software at $1 \mathrm{~mm}$ intervals (corresponding with the millimeter diagram of the rulers) starting from the level of the first interval line previously prescribed.

\section{B. Measuring of the canal diameter at each interval:}

10 additional lines were drawn at 90 degree angles to the internal wall of the canal (at the points of the intersection of the interval lines with the internal wall of the canal) and extended until intersection with the external wall of the canal, these were considered measuring lines, once the position of these lines were finalized, the length of each line was noted and recorded (these measurements 
represented the diameter of the canal at each interval level) .

\section{Measurement of canal taper:}

The canal space was divided into three thirds (apical, middle and coronal), the first measuring line was considered the beginning of the apical third of the canal, while the $4^{\text {th }}$ measuring line was considered the end of the apical third and the beginning of the middle third of the canal. Moreover, the $7^{\text {th }}$ measuring line was considered the end of the middle third and the beginning of the coronal third of the canal, while the $10^{\text {th }}$ measuring line was considered the end of the coronal third of the canal.

The taper of the canal was calculated using the following equation:

$$
\begin{aligned}
& \frac{D 2-D 1}{\text { number of measuring lines }} \times 100 \\
& \mathrm{D}_{2}: \text { most coronal diameter. } \\
& \mathrm{D}_{1}: \text { most apical diameter. }
\end{aligned}
$$

\section{2- Evaluation of the apical diameter:}

The apical diameter of the preparation was evaluated by measuring the diameter of the preparation at a point $(0.566 \mathrm{~mm})$ form the beginning of the divergence of the canal preparation of the original canal (fig. 3).

\section{Statistical Analysis of the data}

Numerical data were explored for normality by checking the distribution of data and using tests of normality (Kolmogorov-Smirnov and ShapiroWilk tests). All data showed normal (parametric) distribution. Parametric data were presented as mean and standard deviation (SD). For parametric data; repeated measures Analysis of Variance (ANOVA) was used to compare between the groups as well as the root levels within each group. Oneway ANOVA test was used to compare between apical diameter in the three groups. Bonferroni's post-hoc test was used for pair-wise comparisons when ANOVA test is significant. The significance level was set at $\mathrm{P} \leq 0.05$. Statistical analysis was performed with IBM SPSS Statistics for Windows, Version 23.0. Armonk, NY: IBM Corp.

\section{RESULTS}

With regards to canal taper, there was no a statistically significant difference between the taper values of the apical and middle third in the three preparation time groups $(P$-value $=0.169)$. Pairwise comparisons between the three preparation time groups at the coronal third revealed that there was no a statistically significant difference between 60s and 90s groups, but both showed a statistically significantly higher mean taper values than 30 s group ( $P$ value $<0.05$ ), figures 1 and 2 . Furthermore, the apical tip diameter showed a significant difference between each of three groups $(P$-value $<0.001)$.

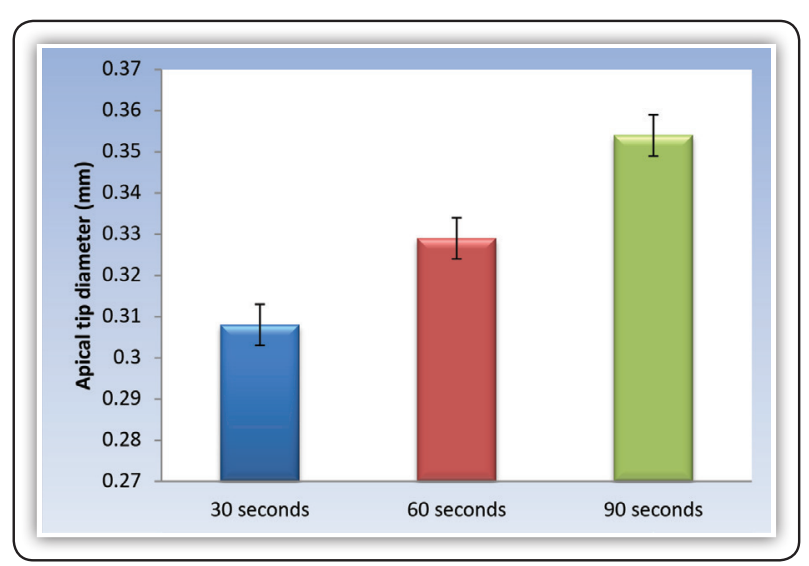

FIG (1) Effect of time on apical tip diameter

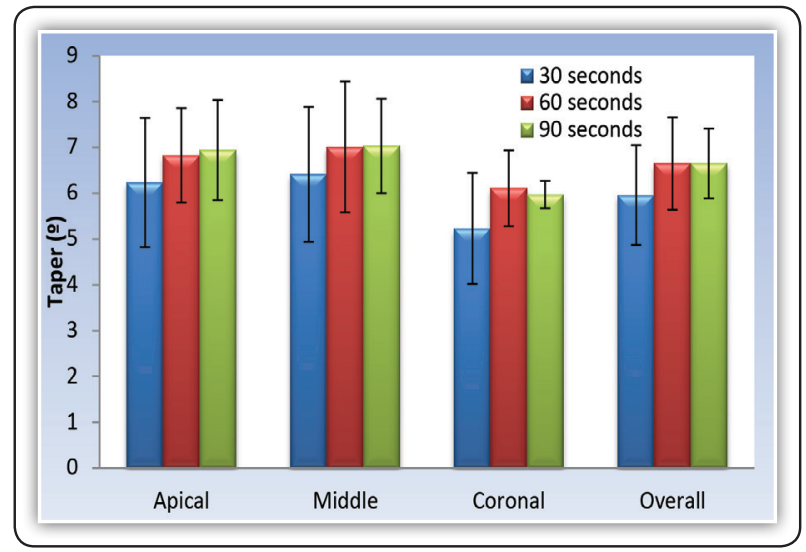

FIG (2) Effect of apical taper and time 


\section{DISCUSSION}

In this study, a total of 54 resin blocks made of clear polyacrylic resin with simulated root canals were used. This number was estimated according to the power analysis done on the data obtained from a study done by Ozyrucc T, et al $2017^{(19)}$. The confidence level was set at $95 \%$ and this corresponded to 18 samples per group. Simulated resin canals were preferred over root canals in natural teeth because in natural teeth it is very difficult to maintain standardization because of the anatomic variations (curvature, taper and length) and hardness dissimilarity of the teeth especially when derived from many different donors ${ }^{(20,21)}$.

The standardization of working length in this study was done using a novel method, a customized teflon stopper to prevent overextension during preparation. The use of a customized stopper is more accurate and more clinically relevant when compared to the other above-mentioned methods. With regards to the preparation environment, the XP endo-shaper is manufactured out of an alloy with an Austinite transition temperature of $35^{\circ} \mathrm{C}$. At this temperature the instrument changes longitudinally to form a wider S-shape, designed to impart a $4 \%$ taper during canal preparation ${ }^{(18)}$. For this reason, studies done at room temperature may be inaccurate when using instruments like this.

To overcome this issue, all preparation procedures were done while submerging the resin blocks in a $37^{\circ} \mathrm{C}$ water bath to allow for the alloy change and to closely mimic clinical conditions, this is similar to other studies done in this field (22,23) Furthermore, the rate of preparation needed to be standardized to minimize variations during preparation. A pilot study was done to evaluate the average time taken to reach the working length using the manufacturer prescribed number of strokes (10 strokes). According to this, the rate of preparation was set to be 2 strokes per 3 second which means it took 15 seconds to complete 10 strokes and reach the working length.
In this study a stereomicroscope was used similar to other studies in this filed ${ }^{(24,25,26,27)}$. Stereomicroscopy was preferred over other methods because of its low cost, availability, simplicity of use and no risk of radiation exposure. With regards to image clarity, stereomicroscopy is superior to other method except $\mu \mathrm{CT}^{(28)}$. In this study, imaging of stereomicroscope was done at $8 \mathrm{x}$ magnification to ensure that the image contained both the simulated canal and ruler within its borders. During measurement of the preparation it became evident that the XPS instrument did not maintain the same working length, this made it difficult to standardize the starting point for measurement of the canal, to overcome this, the booster tip of the XPS instrument was measured and the average length was established to be $(0.566) \mathrm{mm}$. When determining the start point for drawing the first interval line, $0.566 \mathrm{~mm}$ was measured from the beginning of divergence of the canal preparation from the original canal and that point was considered the level first interval line.

The null hypothesis of this study was that using different preparation time will not affect the canal taper and apical diameter, but the null hypothesis was unfulfilled. With regards to the effect of preparation time on simulated root canal taper, when comparing the taper values between the preparation time groups within each simulated root canal third, the coronal taper increased significantly after preparation for 60s and 90s. As previously mentioned, the XPS is an "adaptive core" instrument which is designed to expand to irregular parts of canal space ${ }^{(29)}$ and hence increase the amount of touched canal walls during preparation which ultimately may lead to improved canal cleanliness, this has been proven in previousresearch $^{(30,31,32)}$. 
Furthermore, during the initial 15 seconds of preparation outlined by the manufacturer in which the instrument should reach the full working length, the instrument is tightly bound inside the canal space and no longer retains the snake like shape and will prepare the canal with its $(1 \%)$ core taper. Moreover, during the next 15 seconds the instrument design begins to rotate more freely in the canal allowing the instrument to revert to its snake like shape and impart a larger taper to the canal space.

After preparation for $60 \mathrm{~s}$ and $90 \mathrm{~s}$, a further $60 \mathrm{~s}$ and 90 s, respectively, of free rotation in the canal may have resulted in more contact of the instrument with the canal wall as well as free movement of the instrument during use. Furthermore, once the instrument was free in the canal this may have allowed for more brushing motion of the coronal third of the canal. These reasons together can explain the significant increase in taper of the coronal third. The effect of preparation time and rotational speed on root canal shape has been established previously ${ }^{(33,34,35)}$. Other research done on adaptive core instruments have shown similar results ${ }^{36,37,38}$ ${ }^{39,40)}$. No research done to date on adaptive core instrument has shown the contrary.

With regards to apical diameter, there was a significant difference between all the groups. This could be explained by the fact that the increased preparation time combined with the inherent property of NiTi alloy to exhibit the so called "rebound effect" (41,42) may have resulted in an unbalanced increased cutting in the apical area. The fact that increased preparation time affects apical diameter of root canal is well established for adaptive core instruments ${ }^{(37,38,43)}$. On the other hand, no research to date on adaptive core instruments directly measuring apical diameter has shown the contrary. Moreover, canal transportation inadvertently results in widening of the apical area, multiple research has shown that increasing preparation time or rotational speed can result in canal transportation ${ }^{(44,45)}$. On the other hand, some research has shown preparation time has little effect on transportation ${ }^{(46,47)}$.

According to the manufacturer the XPS instrument should impart a $4 \%$ taper with an apical diameter of an ISO \#30 ${ }^{(18)}$, but the reality of using this instrument revealed that this is not the case. Although the apical size reached an ISO \#30 after preparation using the manufacturer recommendations, the final taper was not a $4 \%$. Furthermore, the effect of increasing working time revealed that the apical diameter of prepared canals would get larger. These conclusions have repercussions on the fit of cones during obturation and the effectivity of irrigation procedures in canals enlarged with XPS.

\section{CONCLUSIONS}

Extended time of preparation when using XPEndo Shaper results in increasing the apical tip diameter and canal taper.

Endnotes

\section{REFERENCES}

1. Azim A, Aksel H, Zhuang T, Mashtare T, Babu J, Huang G. Efficacy of 4 irrigation protocols in killing bacteriacolonized in dentinal tubules examined by a novel confocal laser scanning microscope analysis. Int Endod J 2016; 42:928-34.

2. Yost R, Bergeon B, Roberts M, Roberts H, Himel V, Sabey $\mathrm{K}$. Evaluation of 4 different irrigation systems for apical extrusion of sodium hypochlorite. Int Endod J 2015; 41:1530-4.

3. Carpio A, Kisben A, Felitti R, Bbagiratb A, Medapati M, Lai C, Cunba R. Antibacterial properties of chitosan nanoparticles and propolis associated with calcium hydroxide against single- and multispecies biofilms: an in vitro and in situ study. Int Endod J 2017; 43:1332-6.

4. Bao P, Sben Y, Lin J, Haapasalo M. In vitro efficacy of XP-endo Finisher with 2 different protocols on biofilm removal from apical root canals. Int Endod J 2017; 43:321-5

5. Quality guidelines of endodontic treatment: consensus report of the European Society of Endodontology. Int Endod J 2006; 921-30.

6. Schilder H. Cleaning and shaping the root canal. Dent Clin North Am 1974; 18:269-96. 
7. Martins J, Francisco H, Zapata R. Prevalence of C-shaped configuration in the mandibular first and second premolars: a cone-beam computed tomographic in vivo study. Int Endod J 2017; 43:890-5.

8. Burklein S, Heck R, Scbafer E. Evaluation of root canal anatomy of maxillary and mandibular premolars in selected Greman population using cone-beam computed tomographic data. Int Endod J 2017; 43:1448-52.

9. Arens C, Hoen M, Steiman H, Dietz G. Evaluation of single-use rotary nickel-titanium instruments. Int Endod J 2003; 29:664-6.

10. Parashos P, Messer H. Rotary NiTi instrument fracture and its consequences. Int Endod J 2006; 32:1031-43.

11. Parashos P, Messer H. Questionnaire survey on the use of rotary nickel-titanium endodontic instruments by Australian dentists. Int Endod J 2004; 37:249-59.

12. Burklein S, Mathey D, Schafer E. Shaping ability of ProTaper NEXT and BT-Race NiTi instruments in severely curved root canals. Int Endod J 2015; 48:774-81.

13. Sbi L, Wagle S. Comparing the centering ability of different pathfinding systems and their effect on final instrumentation by Hyflex Cm. Int Endod J 2017; 43:1868-71.

14. Capar I, Erats H, Ok E, Arslan H, Erats E. Comparative study of different novel nickel-titanium rotary systems for root canal preparation in severely curved root canals. Int Endod J 2014; 40:852-6.

15. Shen Y, Zhou H, Zheng Y, Peng B, Haapasalo M. Current challenges and concepts of the thermomechanical treatment of nickel-titanium instruments. Int Endod J 2018; 39:163-72.

16. Toyoglu M, Altunbas D. Influence of different kinematics on apical extrusion of irrigant and debris during canal preparation using K3Xf instruments. Int Endod J 2017; 43:1565-8.

17. XP-endo Shaper product of FKG: https://www.fkg.ch

18.www.info@fkg.ch,info@fkg.ch

19. Ozyurek T, Yilmaz K, Uslue G. Shaping Ability of Reciproc, WaveOne GOLD, and HyFlex EDM Single-file Systems in Simulated S-shaped Canals. J Endod 2017;(1):1-5

20. Peters OA, Laib A, Gohring TN, Barbakow F. Changes in root canal geometry after preparation assessed by highresolution computed tomography. J Endod 2001; 27:1-6.

21. Peterson TB. Comparisons of the shaping abilities of three NiTi file systems using rotational versus reciprocal movements, [Master's thesis]. University of Minnesota, College of Dentistry. 2014.
22. Ozturk B, Atez A, Fixsekcioglu E. Cone-Beam Computed Tomographic Analysis of Shaping Ability of XP-endo Shaper and ProTaper Next in Large Root Canals. Int Endod J 2019; 1: 1-7.

23. Machado A, Guilherme B, Provenzano J, MarcelianoAlves M, Goncalves L, Neves M. Effects of preparation with the Self-Adjusting File, TRUShape and XP-endo Shaper systems, and a supplementary step with XP-endo Finisher R on filling material removal during retreatment of mandibular molar canals. Int Endod J 2019; 52: 709-15.

24. Donnermeyer D· Viedenz A · Schafer E · Burklein S. Impact of new cross-sectional designs on the shaping ability of rotary NiTi instruments in S-shaped canals. Odontology 2020; 108:174-9.

25. Celik G, Maden M, Savgat A and Orhan H. Shaping ability of the profile 25/0.06 and protaper F2 in rotary motion, and reciproc in simulated canals. Peer J 6: e6109.

26. Abu Haimed AS, Abuhaimed TS, Dummer PE, Bryant ST. The root canal shaping ability of WaveOne and Reciproc versus ProTaper Universal and Mtwo rotary NiTi systems. Saudi Endod J 2017; 7:8-15.

27. Silva E, Tameirao M, Belladonna F, Neves A, Souza E, DeDeus G. Quantitative Transportation Assessment in Simulated Curved Canals Prepared with an Adaptive Movement System. J Endod 2015; 1:1-5.

28. (https://www.microscopeinternational.com)

29. https://brasselerusadental.com/products/xp-3d-shaper/

30. Machado A, Guilherme B, Provenzano J, MarcelianoAlves M, alves L, Siqueira J, Neves M. Effects of preparation with the Self-Adjusting File, TruShape and XP-endo Shaper systems, and a supplementary step with XP-endo Finisher R on filling material removal during retreatment of mandibular molar canals. Int Endod J.2019; 52: 709-15.

31. Yigit Ozer S, AdIguzel O, Kaya S. Removal of debris and smear layer in curved root canals using self-adjusting file with different operation times - A scanning electron microscope study. Int Dent Res 2011; 1:1-6.

32. Ribeiro M, Sousa Y, Versiani M, Lamira A, Steier L, Pecora J, et al. Comparison of the Cleaning Efficacy of SelfAdjusting File and Rotary Systems in the Apical Third of Oval-shaped Canals. J Endod 2013; 39:398-401.

33. Schafer E, Erler M, Dammaschke M. Comparative study on the shaping ability and cleaning efficiency of rotary Mtwo instruments. Part 1. Shaping ability in simulated curved canals. Int Endod J.2016;39: 196-202. 
34. Saber S, Nagy M, Schaefer E. Comparative evaluation of the shaping ability of ProTaper Next, iRaCe and Hyflex $\mathrm{CM}$ rotary NiTi files in severely curved root canals. Int Endod J.2015; 48: 131-6.

35. Buerklein S, Boerjes L, Schaefer E. Comparison of preparation of curved root canals with Hyflex CM and Revo-S rotary nickel-titanium instruments. Int Endod J.2015; 47: 470-6.

36. De-Deus G, Belladonna F, Simoes M, Cavalcante D, J. Ramalho C, Souza E, et al. Shaping efficiency as a function of time of a new heat-treated instrument. Int Endod J. 2018; 52: $337-42$.

37. Velozo C, Silva S, Almeida A, Romeiro K, Vieira B, Dantas H, Sousa F, Albuquerque D. Shaping ability of XP-endo Shaper and ProTaper Next in long oval-shaped canals: a micro-computed tomography study. Int Endod J. 2020; 53: 998-1006.

38. Webber M, Piasecki L, Jussiani E, Andrello A, Reis P, A. Azim K, A. Azim A. Higher Speed and No Glide Path: A New Protocol to Increase the Efficiency of XP Shaper in Curved Canals-An In Vitro Study. J Endod 2020; 46: 103-9.

39. Hülsmann M. Preparation of curved root canals with the Self- Adjusting File vs BioRace rotary NiTi-instruments: a comparative study on extracted teeth. ENDO (Lond Engl) 2018;12(3):151-62.

40. Versiani M, Pecora J, Sousa-Neto M. Flat-Oval Root Canal Preparation with Self-Adjusting File Instrument:
A Micro-Computed Tomography Study. J Endod 2011; 37:1002-7.

41. Ha J, Kwak S, Versluis A, Lee C, Park S, Kim H. The geometric effect of an off-centered cross-section on nickel-titanium rotary instruments: A finite element analysis study. Journal of Dental Sciences. 2017; 12: 173-8.

42. ZHOU H, PENG B, ZHENG Y. An overview of the mechanical properties of nickel-titanium endodontic instruments. Endodontic Topics 2015, 29, 42-54.

43. Ates A, Arican B, Isik. Comparison of SHAPING Ability of XP-Endo Shaper in Simulated J-Shaped Canals with Various Sizes. J Res Med Dent Sci; 2020: 8 (4):176-81.

44. Jeon H, Paranjpe A, DDS, Ha J, Kim E, Lee W, Kim H. Apical Enlargement According to Different Pecking Times at Working Length Using Reciprocating Files. J Endod 2014; 40: 281-4.

45. Franco V, Fabiani C, Taschieri S, Malentacca A, Bortolin M, Fabbro M. Investigation on the Shaping Ability of Nickel-Titanium Files When Used with a Reciprocating Motion. J Endod 2011; 37: 1398-401.

46. Goldberg M, Dahan S, Pierre Machtou. Centering Ability and Influence of Experience When Using WaveOne Single-File Technique in Simulated Canals. International Journal of Dentistry 2012; 1: 1-7.

47. Ismail A, Manar Galal. Effect of Different Kinematics of Rotary Niti Instruments on Canal Transportation in Curved Root Canals. Egyptian Dental Journal; 64: 3865-72. 